\title{
Analysis of the Relationship Between Travel Time and on Street Parking
}

\author{
Stella Belinda Kartika Putri ${ }^{a}$, Eduardi Prahara ${ }^{\text {b }}$ \\ a,b Civil Engineering Department, Faculty of Engineering, Bina Nusantara University, Jakarta, Indonesia 11480 \\ a eduardi@binus.ac.id
}

Article History: Received: 10 November 2020; Revised 12 January 2021 Accepted: 27 January 2021; Published online: 5 April 2021

\begin{abstract}
Research describes the effect of the on-street parking to the travel time of vehicle in crossing the road. The case study from this research is in the Jalan H. Agus Salim Jakarta Pusat, where the location is using the on street parking as the type of the parking system. Research method that we used is license plate method for travel time and parking characteristic survey. We used Manual Kapasitas Jalan Indonesia (MKJI) 1997 and linear regression as the based to calculate all the datas. To get the correlation between travel time and on-street parking, we used Correlation Test. With the value of $\mathrm{R}$ more than 0,8 it means the relationship between travel time and on-street parking is very strong. And for the result of the relationship between travel time, flow and capacity we get $\mathrm{Y}=186,24+215,71 \mathrm{X}$, with a $=0,733$. The conclusion from this research is on street parking has strong influence on the travel time of the vehicle to get through to Jalan H. Agus Salim.
\end{abstract}

Keywords: Vehicle Travel Time, Road Body Parking, Number Plate Method, Linear Regression, Correlation Test

\section{Introduction}

Transportation problems in Jakarta is one of the main problems that continue to rise. Moreover, with the passage of time and the development of the city is making increasingly rapid population growth. However, rapid population in the capital is not accompanied by an efficient transport system, coupled with the ease of motor vehicles in Indonesia are increasingly making this city is filled by private vehicle to decrease the level of performance of roads. The situation is aggravated by the absence of parking on the road (on street parking). Parking problems often encountered in the transportation system and greatly affect the movement of vehicles. Parking on the road is one of the causes of congestion arising in Jakarta. The lack of land for construction of parking facilities, the density of activity beside the road in Jakarta, and increased ownership of the vehicle causes the onset of congestion and parking on the road. Parking this type will cause a loss for road users and result in reduced road width, causing disruption to road performance. One of the places in Jakarta with high activity beside the road and part of the way the course is used for parking on the road is Jalan H. Agus Salim Jakarta.

Jalan H. Agus Salim is a street located in the city center and is surrounded by an office area in Jakarta. This road is a travel and culinary center in Central Jakarta. The road is also the connecting roads are impassable for towards the area of Menteng, Setiabudi, Kuningan and Sudirman street. The shops along the two sides of the course without a parking deck for visitors to make motorists must park their vehicles on the road.

In a previous study, entitled "Modeling Travel Time under the Influence of On-Street Parking" by [1], where major cities in China also is a city with a population density very high. In this study a problem that occurs is parking on the road affects the path of cyclists and reduce the capacity of roads. The method used in this study is the license plate survey method as a method of travel time and hazard-based duration model for its data processing. The result showed that the activity-street parking greatly affect the travel time for disrupting beside the road and track to pesepada.

In another study, entitled Modeling the Impact of On-Street Parking on Vehicular Traffic by [2]. The method used in this research is the mathematical methods to determine the impact of the park road to vehicular traffic. The results obtained are in the presence of parking on the road will be detrimental to vehicle traffic of Manila.

What distinguishes this study on two previous studies is research using non-linear regression and to process the data and using correlation and determination to know the relationship between the variables of a parking space. In this research-street parking is divided into several parts of the characteristics of the park so that it can be seen that the parking characteristics which affect more vehicle travel time.

Based on traffic conditions in Jakarta Jalan H. Agus Salim, the problems that occur is how much impact on the capacity of the road due to parking on the road, how much impact that occurs as a result of maneuvering vehicles 
entering and exiting the parking lot, especially when reversed the travel time of vehicles passing through roads, how much influence the road to the parking lot of travel time.

From the results obtained formulation of the problem, the purpose of this study is to determine the impact of the park road to the road capacity, vehicle mileage and travel time.

\section{Research Methods}

The method that we used to complete this study was to perform the following steps:

A. The first stage begins with determining the purpose of the research topic, create limitations on the scope and identify issues to be something that drives this research. The formulation of the problem is amplified by the problems that occur on roads that use the sides of the body of the course as a parking lot.

B. After identifying the problem, do the literature study is to look for theories and references that form the basis for this study.

C. The next step is data collection activities where data obtained by observation in the field such as road geometric conditions are executed manually using the meter, survey the traffic flow by counting the number of cars and motorcycles using the handy counter, and a survey of travel time by using license plate, as well as surveys of environmental conditions, and the activities of existing parking on the road with the method of license plate is recorded every 15 minutes.

D. Based on the collected data, the data processing is done is the data processing volume of traffic, parking conditions, namely turnover and occupancy, as well as the processing of data relating to vehicle travel time by using linear regression and non-linear in Microsoft Excel.

E. Next is the stage of analysis and discussion, at this stage will be analyzing the results of data processing that has been carried out, followed by a discussion. The analysis conducted in this study uses quantitative methods to the traffic volume, average speed, volume parking, parking turnover, occupancy, effective road width and traffic density. Then the discussion was conducted using a linear approach that aims to analyze the impact of parking on the road with travel time. This method also presents a method of analysis that describes the relationship between the duration of a particular region and how different factors can affect the duration. Comparative analysis was also conducted with the aim of comparing the road conditions at the time of no activity and no parking on-street parking activities represented by Saturday at $6 \mathrm{p} . \mathrm{m}$. to 03:00 pm. Then there was a correlation analysis and a determination to get hubngan between variables. This comparison will show how much influence the activity on-street parking on the performance of roads that occurred on Jalan Salim H.Agus Jakarta. Research was also conducted on the vehicle's travel time through Jalan H. Agus Salim Jakarta.

F. After that, the provision of advice or a solution to the condition of Jalan H. Agus Salim order to be able to manage parking on the road well in order to avoid delays that are too long may result in travel time becomes longer.

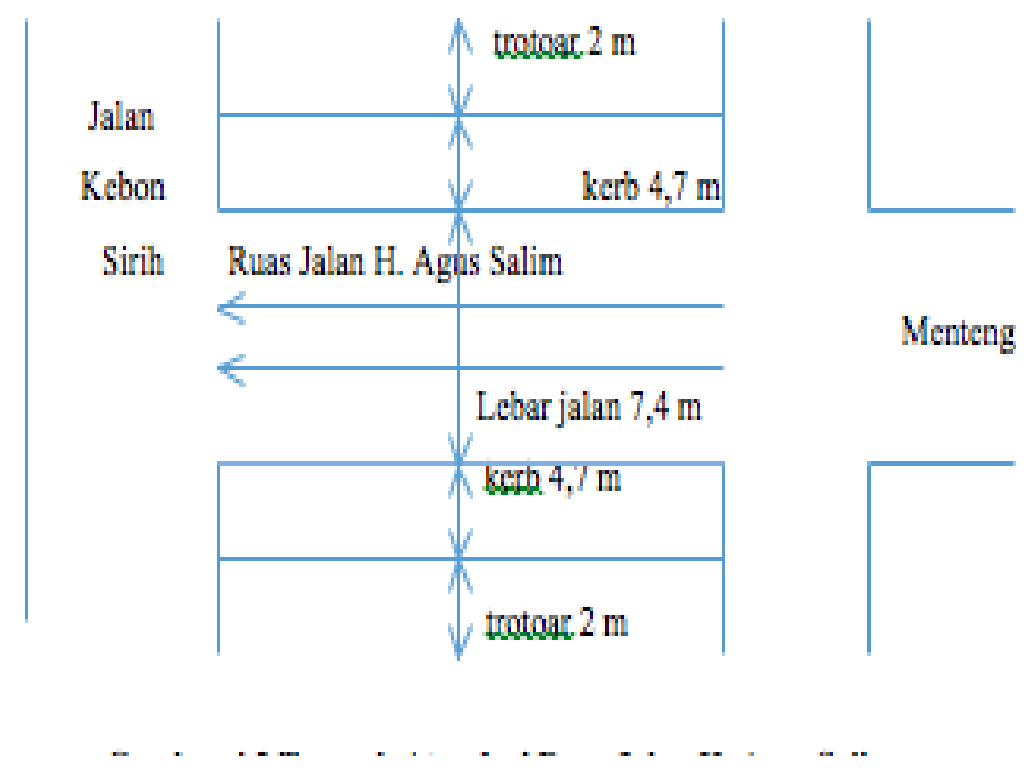


Figure 1. Research Location

\section{Results and Analysis}

Results and discussion on the research carried out by several phases or sections, as to determine the relationship of travel time and parking road must first know the characteristic of traffic flow and parking are also characteristics that can be connected between the travel time to the respective characteristics.

\section{Parking Condition and Road Geometric}

Jalan H. Agus Salim is a place of research is usually called the Jalan Sabang and is a regional center of culinary tourism in Central Jakarta. The right and left road filled with shops and restaurants, while the sidewalks on this road is used by street vendors to sell. These roads have curbs used as a parking lot for vehicles that visit. Time survey conducted on Saturday 18:00 pm - 4:00 pm, because at that time this road becomes one way and it is the peak time of hustle roads.

- $\quad$ Road type: 2/1 UD

- Number of row: 2 rows 1 way without Median

- $\quad$ Width of the Road: 7,4 meters

- $\quad$ Pedestrian Width: 2 meters

- $\quad$ Curb Width: 4,7 meters

- $\quad$ Length of the Road: 400 meters

- Width of the road affected by parking car: 2,27 meters

- $\quad$ Number of parking meter: 11

- $\quad$ Number of Parking Slot: 153 slots

- $\quad$ Parking Slot of Zone 1: 91 slots

- $\quad$ Parking Slot of Zone 2: 62 slots

- $\quad$ Parking condition (angle): angle and parking's line are not controled

Analysis of Traffic Flow

Table 1. Analysis of Traffic Flow

\begin{tabular}{|c|c|c|c|c|c|}
\hline \multirow[b]{2}{*}{ No } & \multirow[b]{2}{*}{ Duration } & \multirow[b]{2}{*}{$\mathbf{L V}$} & \multicolumn{2}{|l|}{ MC } & \multirow{2}{*}{$\begin{array}{l}\text { Flow (Q) } \\
\text { (smp/jam) }\end{array}$} \\
\hline & & & Total & $\begin{array}{l}\text { EMP } \\
=0,4\end{array}$ & \\
\hline 1 & 18:00-19:00 & 343 & 332 & 132,8 & 475,8 \\
\hline 2 & 19:00-20:00 & 434 & 425 & 170 & 604 \\
\hline 3 & 20:00-21:00 & 561 & 457 & 182,8 & 743,8 \\
\hline 4 & $21: 00-22: 00$ & 601 & 508 & 203,2 & 804,2 \\
\hline 5 & $22: 00-23: 00$ & 412 & 589 & 235,6 & 647,6 \\
\hline 6 & 23:00-00:00 & 271 & 404 & 161,6 & 432,6 \\
\hline 7 & 00:00-01:00 & 149 & 333 & 133,2 & 282,2 \\
\hline 8 & 01:00-02:00 & 116 & 265 & 106 & 222 \\
\hline 9 & 02:00-03:00 & 74 & 165 & 66 & 140 \\
\hline 10 & 03:00-04:00 & 61 & 89 & 35,6 & 96,6 \\
\hline \multicolumn{2}{|c|}{ Total } & 3022 & 3567 & 1426,8 & 4448,8 \\
\hline
\end{tabular}

In table 1 above can be seen the highest traffic flow on the street H. Agus Salim is at 21: 00-22: 00 is 804.2 smp / hour. And the lowest is at 03: 00-04: 00 with $96.6 \mathrm{smp} /$ hour. Furthermore, this data will be used to determine the relationship between travel time and degree of saturation.

\section{Analysis of the Road Section's Capacity}

The capacity of roads used in this study is based on the method [3], to 2 lane road one lane on urban roads, 
road capacity for both its lanes are not separated, in contrast to the way a lot of lane capacity is determined per lane. To determine the value of the capacity of the road, things to do is to collect data from the field survey data were then adjusted by a factor of adjustment.

To compare the capacity of the road when there is activity parking and no parking activity at Jalan H. Agus Salim, the adjustment factor also made a difference when there is no activity and no parking. Once known the difference, further analysis of this capacity is used as a parameter for calculating the ratio of travel time, current and capacity of roads.

For more details can be seen in table 4.4 below for analysis of road capacity H. Agus Salim.

Table 2. Analysis of the Road Section's Capacity With and Without On Street parking

\begin{tabular}{llll}
\hline No & Analysis Factor & No Parking & Parking \\
1 & Kapasitas Dasar $\left(\mathrm{C}_{0}\right)(\mathrm{smp} / \mathrm{jam})$ & 2900 & 2900 \\
\hline 2 & Faktor Koreksi akibat Pembagian Arah $\left(\mathrm{FC}_{\mathrm{sp}}\right)$ & 1 & 1 \\
\hline 3 & Faktor Koreksi akibat Lebar Jalan $\left(\mathrm{FC}_{\mathrm{w}}\right)$ & 1 & 0,56 \\
\hline 4 & Faktor Koreksi akibat Gangguan Samping $\left(\mathrm{FC}_{\mathrm{sf}}\right)$ & 0,88 & 0,82 \\
\hline 5 & Faktor Koreksi akibat Ukuran Kota $\left(\mathrm{FC}_{\mathrm{cs}}\right)$ & 1,03 & 1,03 \\
\hline 6 & Kapasitas $(\mathrm{C})=_{\mathrm{C}_{0} \times \mathrm{FC}_{\mathrm{w}} \times \mathrm{FC}_{\mathrm{sp}} \times \mathrm{FC}_{\mathrm{sf}} \times \mathrm{FC}_{\mathrm{cs}}(\mathrm{smp} / \mathrm{jam})}^{2628,56}$ & 1371,63 \\
\hline
\end{tabular}

From table 2 above is clearly seen that on-street parking greatly affect the capacity of roads H. Agus Salim, because the capacity when no parking is $2628.56 \mathrm{smp} / \mathrm{h}$ at which time no activity park road capacity was reduced to $1371.63 \mathrm{smp} /$ hour.

\section{Relationship Between Travel Time, Flow and Degree of Saturatioin}

Once you know the current, capacity and time on the road section H. Agus Salim, then we can figure out to do with analysis using simple linear regression. First data is grouped per hour for flow and capacity using the unit smp / hour, and then find the value of Q / (C-Q) or the degree of saturation to determine the ratio of traffic flow with the rest of the capacity of the road when the vehicle passed, then the result of the calculation is were used as independent variables, while the travel time as variables are not free.

Table 3. Analysis of the Relationship Between Travel Time, Flow and Degree of Saturation

\begin{tabular}{|c|c|c|c|c|c|}
\hline $\begin{array}{l}\text { No } \\
\text {. }\end{array}$ & Durasi & $\begin{array}{l}\text { Waktu Tempuh } \\
\text { Tq (detik) } \\
\text { Y }\end{array}$ & $\begin{array}{l}\text { Arus } \\
\mathbf{Q}(\mathbf{s m p} / \mathbf{j a m})\end{array}$ & $\begin{array}{l}\text { Kapasitas } \\
\text { C (smp/jam) }\end{array}$ & $\begin{array}{l}\text { Derajat } \\
\text { Kejenuhan } \\
\text { Q/(C-Q) } \\
\text { X }\end{array}$ \\
\hline 1 & 18:00-19:00 & 314 & 475,80 & 1372 & 0,53 \\
\hline 2 & 19:00-20:00 & 384 & 604,00 & 1372 & 0,79 \\
\hline 3 & $20: 00-21: 00$ & 395 & 743,80 & 1372 & 1,18 \\
\hline 4 & $21: 00-22: 00$ & 468 & 804,20 & 1372 & 1,42 \\
\hline 5 & $22: 00-23: 00$ & 387 & 647,60 & 1372 & 0,89 \\
\hline 6 & 23:00-00:00 & 412 & 432,60 & 1372 & 0,46 \\
\hline 7 & 00:00-01:00 & 270 & 282,20 & 1372 & 0,26 \\
\hline 8 & 01:00-02:00 & 220 & 222,00 & 1372 & 0,19 \\
\hline 9 & 02:00-03:00 & 164 & 140,00 & 1372 & 0,11 \\
\hline 10 & 03:00-04:00 & 124 & 96,60 & 1372 & 0,08 \\
\hline \multicolumn{2}{|c|}{ Rata-rata } & 313,75 & & & 0,09 \\
\hline
\end{tabular}




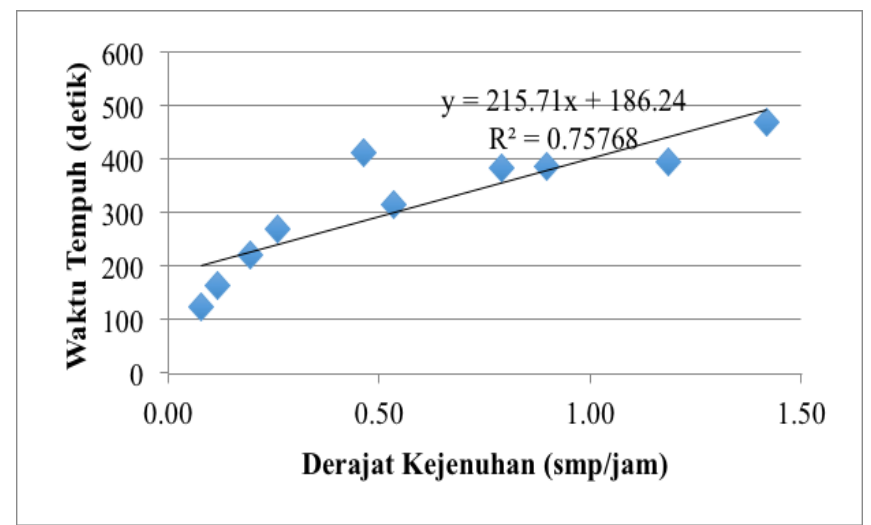

Figure 1. Relationship Between Travel Time and Degree of Saturation

It was found that $\mathrm{R}^{2}$ is equal to 0.75768 , which means the $\mathrm{R}$ is 0.87045 . With the value of $\mathrm{R} 0.87045$ travel time relationship, and the degree of saturation included in the criteria for the correlation is very strong where the flow and capacity greatly affect the travel time of vehicles to pass roads H. Agus Salim

Results of linear regression is then is to determine the course of service level index.

Regresi linear $=\mathrm{Y}=186,24+215,71 \mathrm{X}$

Konstanta B (dari regresi linear) $=215,71$

$$
\begin{aligned}
\text { Konstanta } \mathrm{A}=(\overline{\mathrm{Y}}-\mathrm{B} \overline{\mathrm{X}}) & =313,75-215,71(0,09) \\
& =294,28
\end{aligned}
$$

Level of service (a) $\quad=B / A$

$$
\begin{aligned}
& =215,71 / 294,28 \\
& =0,733
\end{aligned}
$$

With the value of the level of service (a) 0.733 means in accordance with the table 2.9 category of service index H. Agus Salim is a category D is approaching unstable flow conditions are affected by the change - change in circumstances which considerably lowers the speed of travel is quite large. From the results of the index level of service with a category D means there is another factor that makes the travel time becomes longer is factorstreet parking.

\section{Analysis of the Relationship Between Travel Time and on Street Parking}

In this study, to connect the two variables was used the analysis of correlation, if the variable of the other variables correlated with high or low each other. The higher the correlation, the higher the correlation between the two variables.

In terms of finding a correlation value, it would be better to use the value of the highest correlation between several methods. To connect each variable, in this study using two methods, namely methods of linear and nonlinear method is by exponential. So that later can be seen the value of $\mathrm{R}$ on which method is the highest.

\section{With Linear Method}

In this section analysis to locate the model and correlation between variables using simple linear is $\mathrm{Y}=\mathrm{A}+$ $\mathrm{BX}$, where $\mathrm{Y}$ as the dependent variable is the travel time and $\mathrm{X}$ would be the independent variable or variables that affect variable $\mathrm{Y}$, respectively parameter-street parking and it will be known after the correlation (R) and the coefficient of determination $\left(\mathrm{R}^{2}\right)$.

In this section will discuss all relationships between travel time and the characteristics of the road is a parking maneuver activity, accumulation of parking, occupancy, parking and turnover indices parking with the linear method. 


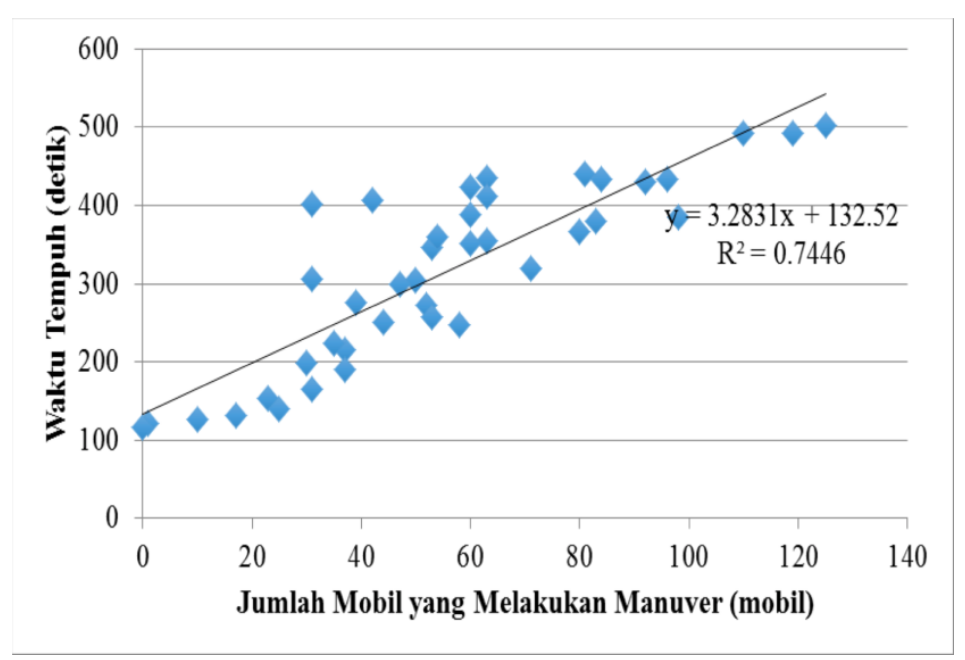

Figure 2. Relationship Between Travel Time and Parking Maneuver

It can be seen that in this relationship produces $\mathrm{R}^{2}$ value of 0.74456 means of $74.456 \%$ variation from the vehicle travel time can diterangan with the variation of the number of vehicles parking maneuver, while the remaining $25.544 \%$ is influenced by other variables. Or a common language that the effect of maneuvering a vehicle parked on car travel time amounted to $74.456 \%$, while the remaining $25.544 \%$ is influenced by other factors.

With a value of $\mathrm{R} 2$ value of 0.74456 means that the $\mathrm{R}$ is 0.863 , which means the relationship between travel time to maneuver the vehicle is very high, meaning that the number of vehicles that maneuver will greatly affect a vehicle to pass through roads H. Agus Salim.

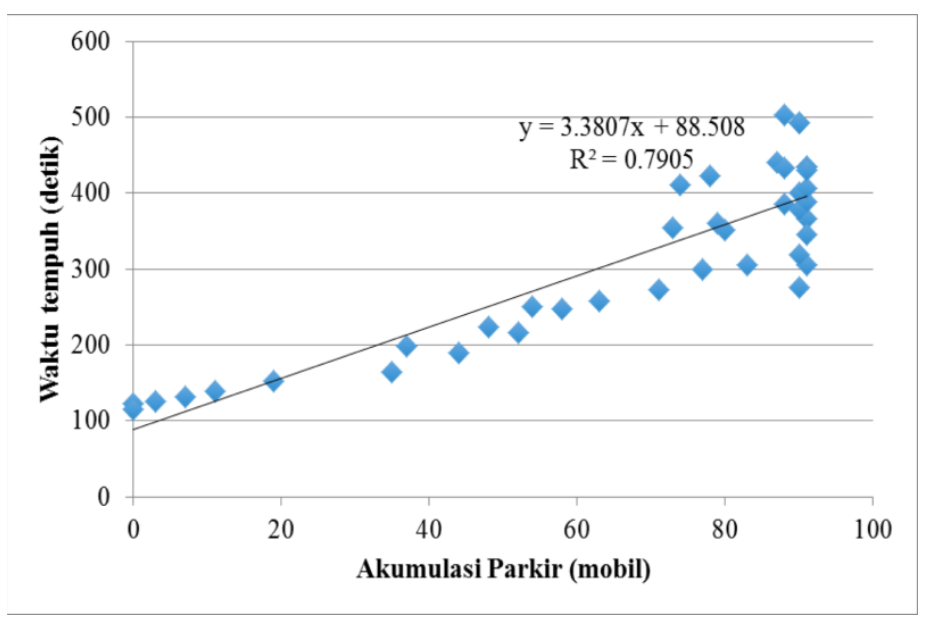

Figure 3. Relationship Between Travel Time and Parking Accumulation Zone 1

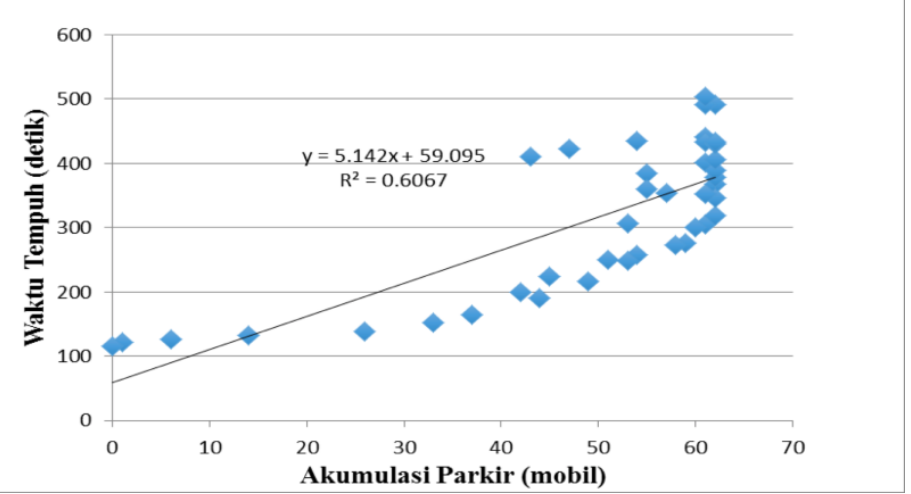

Figure 5. Relationship Between Travel Time and Parking Accumulation Zone 2 


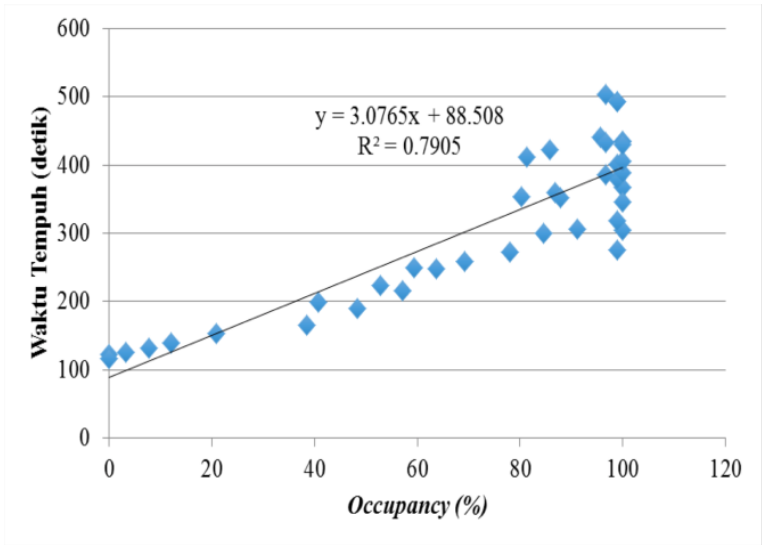

Figure 6. Relationship Between Travel Time and Occupancy Zone 1

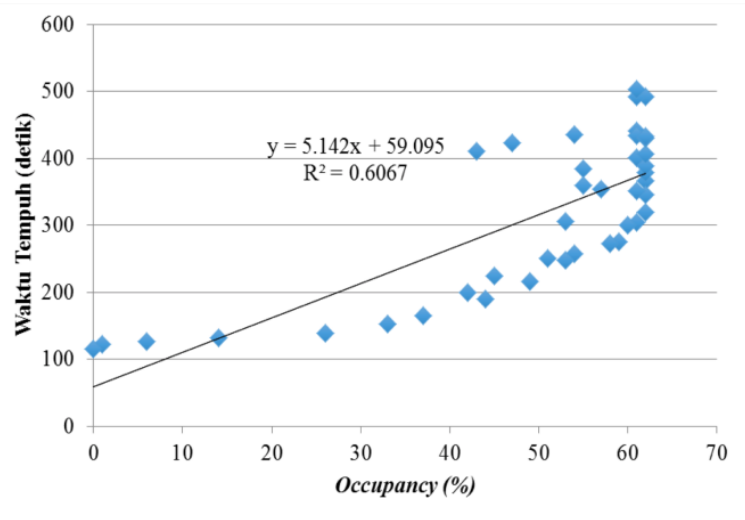

Figure 7. Relationship Between Travel Time and Occupancy Zone 2

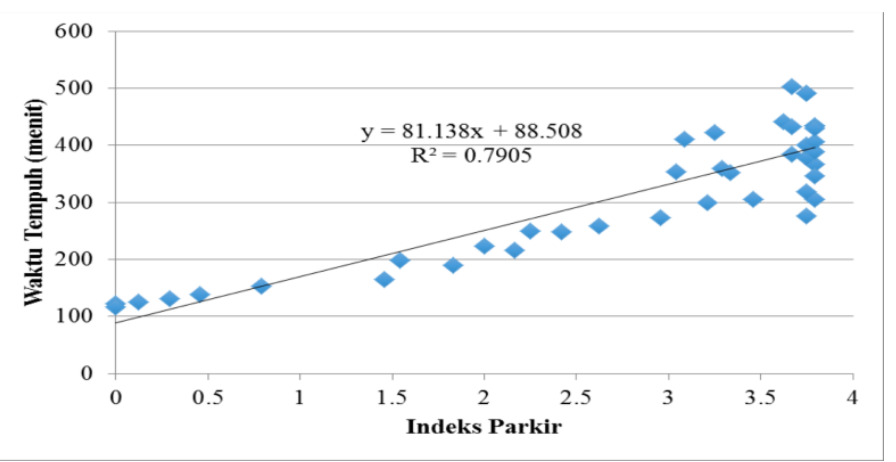

Figure 8. Relationship Between Travel Time and Parking Index Zone 1

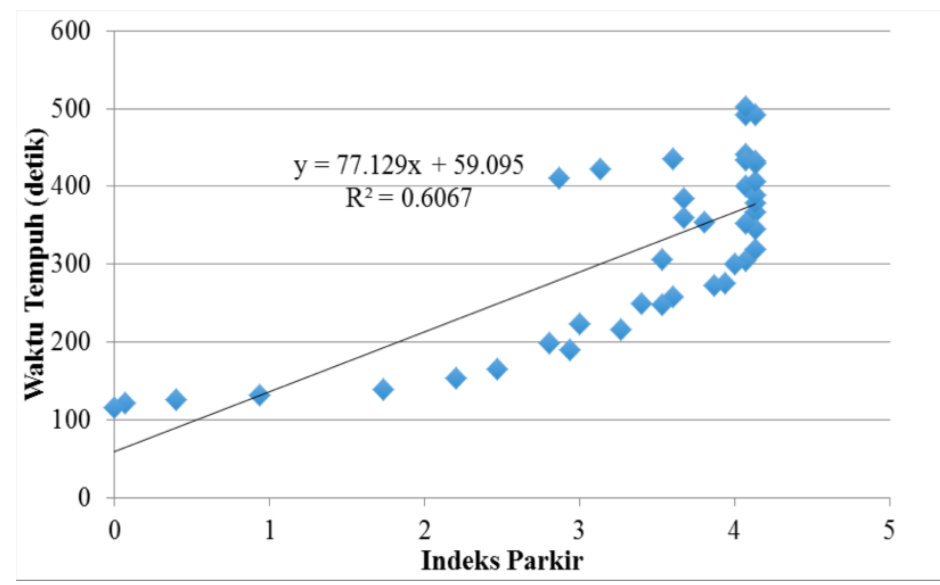

Figure 9. Relationship Between Travel Time and Parking Index Zone 2 
Based on Figure 4, Figure 6 and Figure 8 it can be seen that the value of R2 obtained for accumulation, occupancy, and parking index in zone 1 is 0.7905 means by $79.05 \%$ variation from the vehicle travel time described with a variation of the index-parking zone 1, while the remaining $20.95 \%$ influenced by other variables. Or a common language that the effect of the accumulation, occupancy and parking index in zone 1 on travel time the car is at $79.05 \%$, while the remaining $20.95 \%$ influenced by other factors.

With a value of R2 0.7905 then the R value is 0.889 , which means the correlation between the two variables on this relationship is very strong, with a mean value of R 0.889 accumulation, occupancy and parking index in zone 1 is very influential on the length of travel time of a vehicle in the crossing road research.

Meanwhile, based on Figure 5, Figure 7 and Figure 9 can be seen that the value of R2 obtained for accumulation, occupancy and parking index zone 2 is the mean of $60.6670 .60667 \%$ variation from the vehicle travel time described with a variation of the index of parking in zone 2, while the remaining $39.333 \%$ is influenced by other variables. With R2 obtained is 0.60667 mean value of $\mathrm{R}$ is 0.779 , which means the correlation between the two variables in this relationship is strong, with a mean value of $\mathrm{R} 0.779$ accumulation, occupancy and parking index in zone 2 has a strong influence on the length of travel time of a vehicle in a road crossing research avenues.

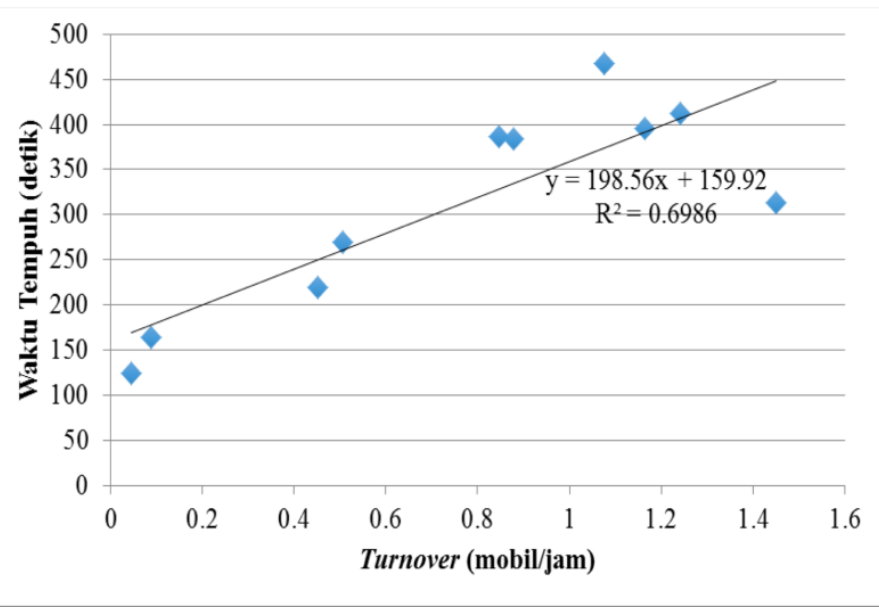

Figure 10. Relationship Between Travel Time and Turnover Zone 1

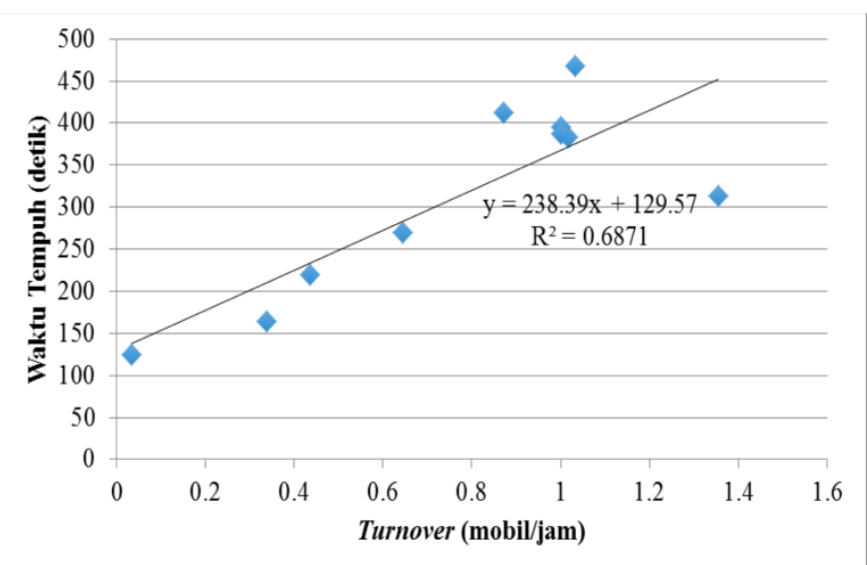

Figure 11. Relationship Between Travel Time and Turnover Zone 2

$\mathrm{R}^{2}$ value obtained is the mean of $69.8570 .69857 \%$ variation from the vehicle travel time described with a variation of the turnover of parking the vehicle in zone 1 , while the remaining $30.143 \%$ is influenced by other variables. With $\mathrm{R}^{2}$ obtained is 0.69857 mean $\mathrm{R}$ value is 0.836 , which means the correlation between the two variables on this relationship is very strong. With the $\mathrm{R}$ value means turnover 0,836 parking zone 1 very strong influence on the length of travel time a vehicle crosses the road in the research.

$\mathrm{R}^{2}$ value obtained is the mean of $68.7140 .68714 \%$ variation from the vehicle travel time can described with a variation of the turnover of vehicles parking in zone 2, while the remaining $31.286 \%$ is influenced by other variables. With $\mathrm{R}^{2}$ obtained is 0.68714 mean $\mathrm{R}$ value is 0.829 , which means the correlation between the two 
variables on this relationship is very strong. With $0,829 \mathrm{R}$ value means turnover of parking in zone 2 very strong influence on the length of travel time a vehicle crosses the road in the research.

\section{With Non Linear Method}

To obtain a good correlation, it is necessary to test the correlation with several methods, in this study after using the linear method, the next is a method of non-linear with the exponential method. Just as the section of linear method, in this section will analyze travel time relationship with all the characteristics of parking with nonlinear method.

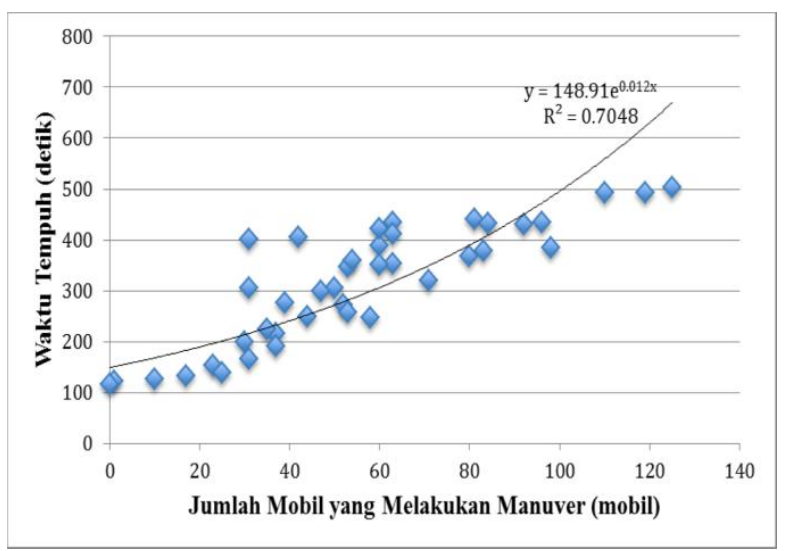

Figure 12. Relationship Between Travel Time and Parking Maneuver Zone 1

Based on the figure 12 above it can be seen that the value of $\mathrm{R}^{2}$ in this relationship is 0.70481 , which means the effect of the maneuver vehicles on travel time amounted to $70.481 \%$. With a value of R2 0.7048 means the $\mathrm{R}$ value is 0.840 . With the $\mathrm{R}$ value 0.840 means the relationship between travel time by maneuvering the car is very strong, which means the vehicle maneuver is very influential on the delay which resulted in increased travel time.

When compared with the value of $\mathrm{R}$ on the linear method amounted to 0.863 , the value of $\mathrm{R}$ with non-linear method is smaller, meaning the relationship between these two variables is linear, although the difference is very small at only 0.023 adrift smaller than the linear method.

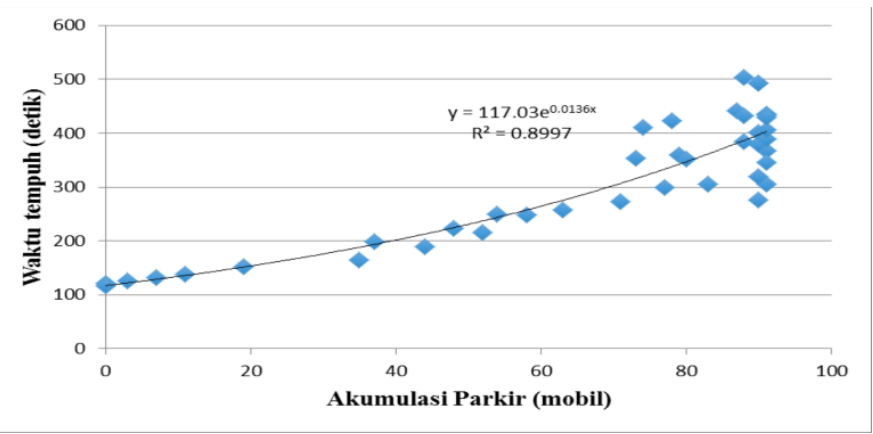

Figure 13. Relationship Between Travel Time and Parking Accumulation Zone 1

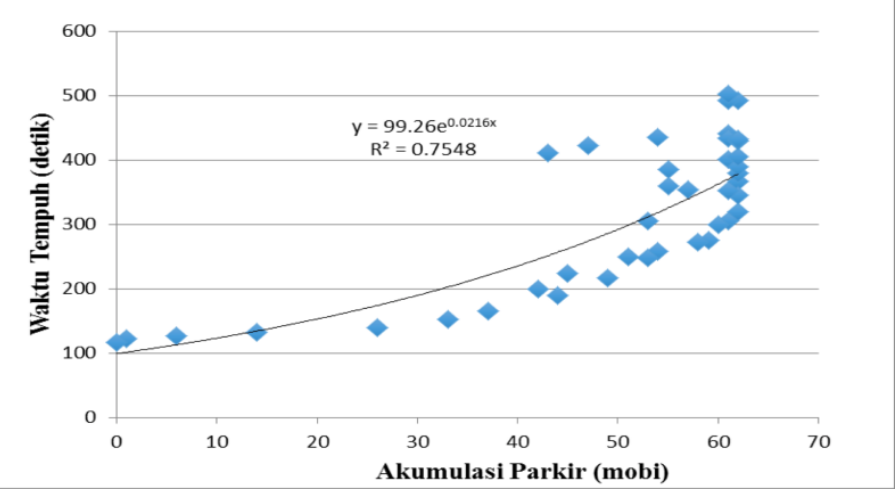

Figure 14. Relationship Between Travel Time and Parking Accumulation Zone 2 


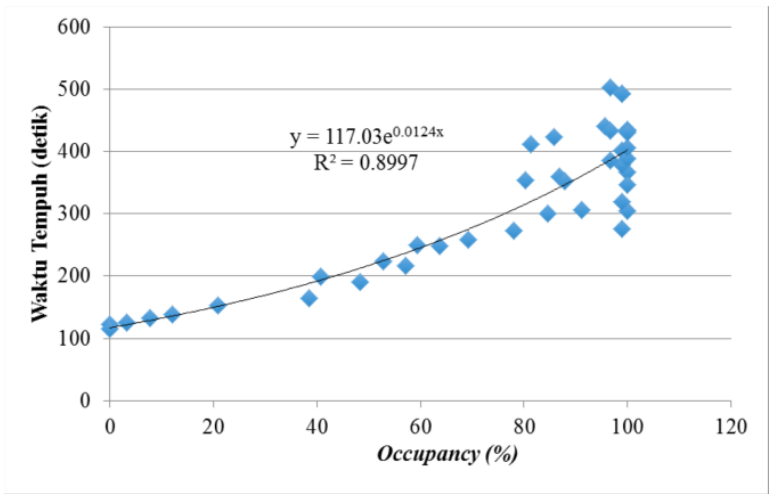

Figure 15. Relationship Between Travel Time and Parking Occupancy Zone 1

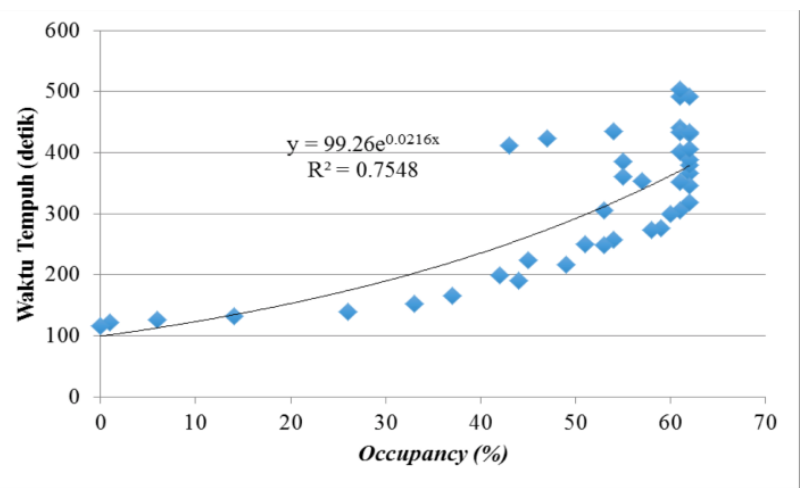

Figure 16. Relationship Between Travel Time and Parking Occupancy Zone 2

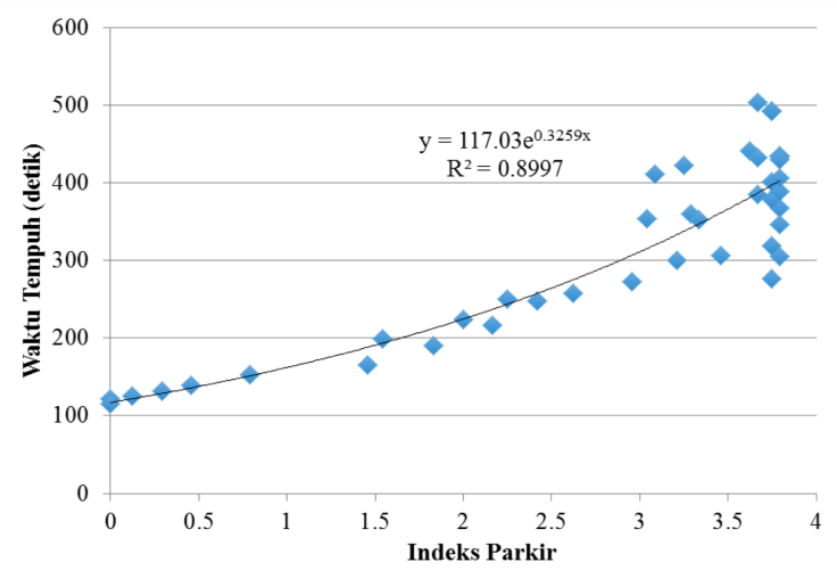

Figure 17. Relationship Between Travel Time and Parking Index Zone 1

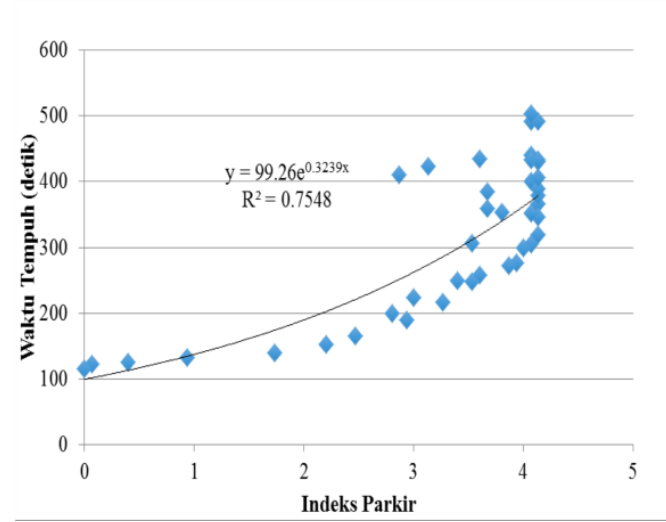

Figure 18. Relationship Between Travel Time and Parking Index Zone 2 
Based on the picture 13, picture 15 and picture 17 above it can be seen that the value of $\mathrm{R}^{2}$ for accumulation, occupancy and parking index in zone 1 is 0.8997 , which means the effect of parking index for zone 1 on travel time amounted to $89.97 \%$. means the $\mathrm{R}$ value is 0.949 . With the $\mathrm{R}$ value 0.949 means the relationship between the travel time index 1 parking zone is very strong, which means the accumulation, occupancy and parking index in zone 1 is very strong influence on the delay which resulted in increased travel time.

When compared with the value of $\mathrm{R}$ on the linear method, the value of $\mathrm{R}$ with non-linear method is larger and closer to the numbers 1 , means the relationship between these two variables to be non linear.

Based on the picture 14, picture 16 and picture 18 for accumulation, occupancy and parking index in zone 2 above can be seen that the value of $\mathrm{R}^{2}$ in this connection is 0.75479 , which means the effect of the accumulation, occupancy and index 2 parking zone on travel time amounted $75.479 \%$. It also means the $\mathrm{R}$ value is 0.869 . With the $\mathrm{R}$ value 0.869 means the relationship between the accumulated travel time, occupancy and parking index zone 2 is very strong, which means the index parking zone on two very strong influence on the delay which resulted in increased travel time. When compared with the value of $\mathrm{R}$ on the linear method, the value of $\mathrm{R}$ with non-linear method is larger and closer to the numbers 1, means the relationship between these two variables to be non linear.

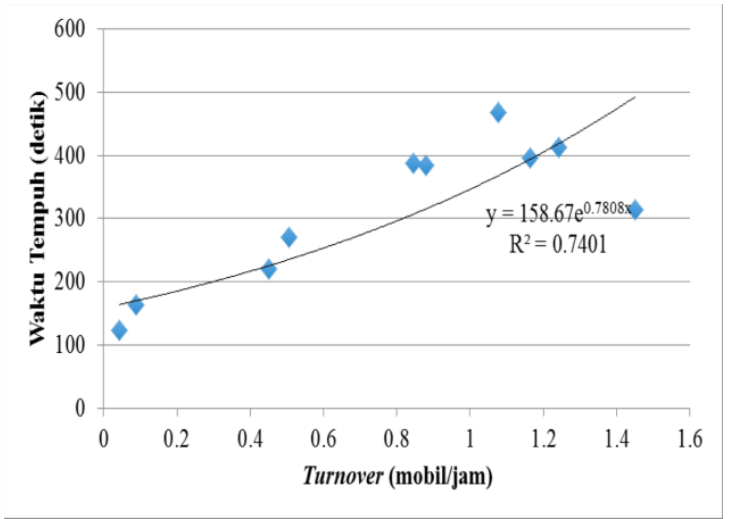

Figure 19. Relationship Between Travel Time and Parking Turnover Zone 1

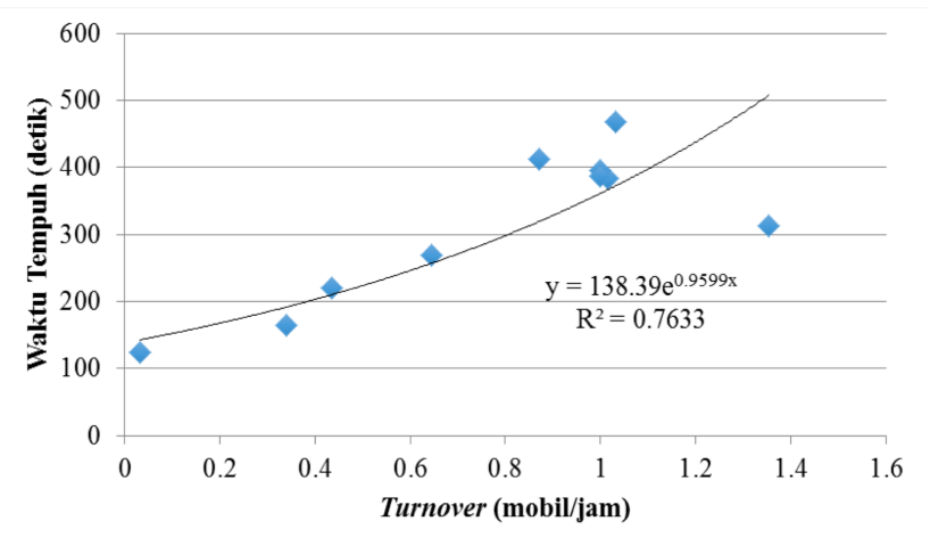

Figure 20. Relationship Between Travel Time and Parking Turnover Zone 2

Based on the figure 19 above it can be seen that the value of $\mathrm{R}^{2}$ in this connection is 0.74007 , which means the effect of turnover in zone 1 on travel time amounted to $74.007 \%$. It also means the $\mathrm{R}$ value is 0.860 . With the $\mathrm{R}$ value 0.860 means the relationship between travel time with a turnover parking zone 1 is very strong, which means the turnover of parking in zone 1 is very strong influence on the delay which resulted in increased travel time. When compared with the value of $\mathrm{R}$ on the linear method, the value of $\mathrm{R}$ with non-linear methods have been bigger though only 0,024 different course, means that the relationship between these two variables to be non linear.

Based on the figure 20 above can be seen that the value of $\mathrm{R}^{2}$ in this connection is 0.76328 , which means the effect of turnover on zone 2 on travel time amounted to $76.328 \%$. It also means the $\mathrm{R}$ value is 0.875 . With the $\mathrm{R}$ value 0.875 means the relationship between travel time with parking turnover Zone 2 is very strong, which means the turnover of parking in zone 2 very strong influence on the delay which resulted in increased travel time. When compared with the value of $\mathrm{R}$ on the linear method, the value of $\mathrm{R}$ with non-linear methods have been bigger 
though only 0,046 different course, means that the relationship between these two variables to be non linear.

Based on data from the above analysis, the correlation value is highest between the accumulated travel time, occupancy, and parking index in zone 1 is equal to 0.949 . Characteristic values of the three has the same value as the value of occupancy and parking index obtained from the accumulation. This means, Effect of accumulation, occupancy and parking index in zone 1 on travel time is so great that it could lead to delay long enough to drive past the road H. Agus Salim Jakarta.

The correlation value accumulation, occupancy and indexes parking zone 1 is higher than zone 2 for the number of parking slots is more prevalent in zone 1 is 91 slots compared to zone 2, which is 62 slots, so that the activities of the parking zones in zone 1 automatically more than zone 2 ,

Then the characteristics of a more decisive result in the length of the delay is achieved vehicles travel time for crossing the research is accumulated, occupancy and parking index for the level of use of parking slots on the street H. Agus Salim.

\section{Conclusion}

Based on the results of data processing and data analysis has been done, it can be concluded as follows:

A. There is a difference high enough road capacity when there is no activity when there's parking and parking activities, namely when there is activity the way parking capacity is $1372 \mathrm{smp} /$ hour whereas when there is no activity park path capacity is $2629 \mathrm{smp} /$ hour.

B. Relationships travel time, traffic flow and the degree of saturation:

- Due to the activities of the parking, the longest time is 503 seconds, which occurred at 21:45 to 22:00 pm, while the travel time was 116 seconds basically occurs when there is no activity park.

- The relationship between travel time, current and capacity to produce a linear regression model $\mathrm{Y}=$ $186.24+215.71 \mathrm{X}$

Where: $\mathrm{Y}=$ Time:

$\mathrm{X}=\mathrm{A}$ comparison between the current and the remaining capacity

Which means that the value of the index level of service (a) is 0.733 with this value, service category the course belongs to the category $\mathrm{D}$ which means instability and hampered.

- The results of correlation test of the relationship between travel time and the degree of saturation is $\mathrm{R}=$ 0.87045 . For the results of correlation between travel time and traffic flow was $\mathrm{R}=0.931$ which means the relationship between variables is very strong, so that the degree of saturation and traffic flow greatly affect the travel time.

C. The relationship between travel time to maneuver the vehicle in accordance with the correlation test used is the correlation value $(\mathrm{R})$ with the linear method, $\mathrm{R}=0.863$ which means the vehicle maneuver very strong influence on his long travel time of a vehicle to traverse the roads H. Agus Salim, Jakarta.

D. The relationship between the travel time to the characteristics of parking on the road is divided into:

- Relations with the accumulated travel time, occupancy, and parking index.

- Based on the results of correlation that has been done in Chapter 4 for the analysis of accumulation, occupancy and indexes parking, the value of $\mathrm{R}$ used is rated $\mathrm{R}$ by the method of non-linear ie for zone 1 with a value of $R=0.949$ and for zone 2 with a value of $R=0.869$, which means accumulated parking very strong influence on the travel time.

- $\quad$ Relationships travel time with parking turnover

- Based on the results of correlation that has been done in chapter 4, the value of the highest correlation to the relationship the travel time and the turnover of parking is a correlation value on a non linear with a value of $\mathrm{R}$ $=0.860$ for Zone 1 and $\mathrm{R}=0.875$ in zone 2 , the turnover of parking affects very high on travel time of a vehicle to pass through roads H. Agus Salim.

- The result of the correlation between travel time to the characteristics of parking on the road no one reaches 1 because there are other parameters that affect the occurrence of delay resulting length of travel time factors other than parking on the road, but with all the relationship is very strong, meaning parking on the road is 
the largest and main cause of the delay resulting length of travel time a vehicle to pass through roads H. Agus Salim.

Based on the analysis and discussion that has been done, it is recommended:

A. Need to use roads or lands another left blank in the vicinity of Jalan H. Agus Salim in order to reduce excess vehicle parked in Jalan H. Agus Salim, such as land left blank on Jalan Thamrin that can be used as a parking location. Or by closing Jalan Salim H.Agus on Saturdays at 18:00 to 3:00 for the conduct current in one direction only still pose a considerable delay.

B. There should be further research is more specific to activities other than parking on the side of the road, such as the factor of people crossing the road, street vendors and the factors slowing the vehicle to look for parking.

Further research is needed to assess the area that could be used as an alternative diversion of excess parked vehicles on these roads.

\section{References}

H. Guo, "Modeling Travel Time under the Influence of On-Street Parking," J. Transp. Eng., 2012.

M. Lim, Modeling the Impact of On-Street Parking on Vehicular Traffic. Atrans Symposium Student Chapter Session. Thailand, 2012.

D. J. B. M. D. B. J. K. Jakarta, Manual Kapasitas Jalan Indonesia (MKJI). Jakarta, 1997. 